\title{
A agrofloresta e os contornos de um sujeito (re)significado
}

\section{The agroforestry and the contours of a subject (re)meaning}

\author{
José Edmilson de Souza Lima ${ }^{1}$ \\ Priscila Cazarin Braga ${ }^{2}$ \\ Rômulo Macari da Silva ${ }^{3}$
}

\begin{abstract}
Resumo
O objetivo do artigo é refletir acerca das possibilidades de emergência de um sujeito constituído a partir de práticas agroflorestais. Para tanto, recorre-se à técnica de história oral de agricultores quilombolas, que usam práticas agroflorestais para coexistir face os desafios da sociedade englobante. O sujeito que irrompe da prática agroflorestal é o sujeito que se (re)significa à medida que reinventa a si mesmo e a própria agrofloresta.
\end{abstract}

Palavras-chave: Agrofloresta. Sujeito agroflorestal.

\begin{abstract}
This article asks to what extent agroforestry, to enable the emergence of a subject agroforestry, this once formed, enables consolidation of agroforestry, continuing a recursive process. It is based on the analysis of dialogic testimonials from farmers maroons who use agroforestry practices to coexist face the challenges of society encompassing. The guy who breaks out of the practice of the Agroforestry is the guy who (re)means while he reinvents himself and own agroforest.
\end{abstract}

Keywords: Agroforestry. Subject agroforestry.

\section{Introdução}

No contexto global de crise civilizatória com rebatimentos econômicos, sociais, políticos, éticos e ambientais, há que se estar atento para o fato de que muito do que se escreve sobre a história de populações que foram alijadas para as margens pela excludente "sociedade englobante" (WANDERLEI, 2000, 2003), está centrado nas categorias de exploração, de colonização e de dominação. Sem deixar de reconhecer que esta "herança colonizadora" projeta-se como um obstáculo, é

\footnotetext{
${ }^{1}$ Pós-Doutor em Meio ambiente e Desenvolvimento (PPGMADE-UFPR). Pesquisador/docente do Mestrado em Direito (UNICURITIBA). E-mail: zecaed@hotmail.com.

${ }^{2}$ Mestre em Meio Ambiente e Desenvolvimento (PPGMADE-UFPR). E-mail: pri13luas@yahoo.com.br. ${ }^{3}$ Mestre em Meio Ambiente e Desenvolvimento (PPGMADE-UFPR). E-mail: penaverde@yahoo.com.br.
} 
importante tornar visíveis algumas estratégias que tais populações elaboram para continuar coexistindo às margens da sociedade englobante, clamando sempre por certo nível de autonomia. A sociedade global está mais próxima do adjetivo excludente do que do englobante e isso obriga as populações alijadas - englobadas às avessas ou pela porta dos fundos - a se reinventarem.

Nesta perspectiva, a ideia de estudar os contornos do sujeito agroflorestal está associada à capacidade dessas populações se autoafirmarem e se autotranscenderem em relação ao ambiente sociocultural e biofísico colonizado pela sociedade englobante. Se no primeiro estágio, o estágio da autoafirmação, o sujeito (dis)socia-se do ambiente para instituir sua identidade, no segundo estágio, o da autotranscendência, ele se (re)concilia, admitindo sua dependência em relação ao ambiente. Identificar os contornos desse sujeito implica identificar como se dá essa tensão permanente entre (dis)sociação e (re)conciliação com o ambiente. A ênfase na identificação dos contornos do sujeito agroflorestal está relacionada à necessidade de fugir à tentação de localizar a "essência" dos sujeitos. Em vez da "essência", buscam-se aqui as formas de expressão concreta desses sujeitos.

Neste sentido, a despeito dos obstáculos impostos pela sociedade englobante, a ideia central deste artigo é verificar em que medida a agrofloresta, ao possibilitar a emergência de um sujeito agroflorestal, este, uma vez constituído, possibilita a consolidação da agrofloresta como alternativa concreta aos processos de reprodução material e imaterial dos agricultores, dando continuidade a um processo recursivo. O sujeito que irrompe da prática agroflorestal é um sujeito (re)significado, pois ao reinventar a si mesmo, reinventa a própria agrofloresta.

\section{Método}

Trata-se de uma pesquisa qualitativa realizada por meio de história oral (ICHIKAWA; SANTOS, 2006), com uma amostra selecionada pelo critério da adesão (YIN, 2005). Dos catorze entrevistados, doze são agricultores e dois técnicos que trabalham com agrofloresta na região pesquisada. Por se tratar de uma pesquisa centrada em um fundamento epistêmico empirista, em cada história oral colhida buscou-se identificar a existência de alguma relação entre a prática agroflorestal e a emergência do sujeito, com vistas a refletir acerca dessa relação. 


\section{Contornos do sujeito}

Nesta seção são apresentados alguns dos elementos que permitem estabelecer os contornos de uma nova concepção de sujeito. Esta seção é a referência para o diálogo com os depoimentos colhidos e a identificação dos possíveis contornos do sujeito agroflorestal.

\subsection{Anúncios de outra agricultura}

$\mathrm{Na}$ perspectiva de Fonini (2012), a questão alimentar, gerada pela transformação dos sistemas de produção de alimentos e respectivas mudanças nas relações socioambientais e culturais no campo, ao longo das duas últimas décadas do século $\mathrm{XX}$, denuncia o processo de distribuição desigual dos benefícios e malefícios da modernização da agricultura. Longe de estarem plenamente estabelecidas, as populações rurais veem-se ainda ameaçadas pelo acirramento do projeto de modernização e crescimento representado, sobretudo, pela intensificação das novidades herdadas da Revolução Verde. ${ }^{4}$

A Revolução Verde no Brasil pode ser entendida como "um programa de remoção dos obstáculos à entrada do capital no campo, de estímulo à modernização da agropecuária" (MARTINS, 1986, p. 94), processo este levado a cabo, sobretudo, pelos governos militares, entre 1964 e 1984, aliados aos grandes capitalistas e também aos donos de terras. Diante da Revolução Verde, os agricultores que não dispunham de capital financeiro para consumir as novas tecnologias dificilmente permaneceram no campo, o que gerou a perda do controle da produção agrícola pela população local, a concentração fundiária e a exclusão dos camponeses (ASSIS, 2006; GLIESSMAN, 2002).

Para compreender a organização moderna da agricultura, Ploeg (2008) caracteriza o sistema de monocultivo como a emergência de um "Império", entendido como um modelo de ordenamento com tendências para instituir-se como dominante. Algumas das características marcantes para o "império" seriam a escala mundial de abrangência e o somatório de expressões centralizadas com objetivos

\footnotetext{
${ }^{4}$ Refere-se ao modelo agrícola idealizado pelo estadunidense Norman Ernest Bourlag (1914-2009), Prêmio Nobel da Paz de 1970. Caracteriza-se pelo grande número de insumos agrícolas, sementes selecionadas, fertilizantes, maquinário e enorme input hídrico e energético. Sendo altamente capitalizado, esse modelo atuou de modo a marginalizar a pequena agricultura camponesa e acirrar as desigualdades no meio rural (MARTíNEZ-ALÍER, 2011, p.184).
}

Cad. de Pesq. Interdisc. em Ci-s. Hum-s., Florianópolis, v.14, n.104, p.25-46, jan/jun 2013 
econômicos e instrumentais. Tal ordenamento partiu do pressuposto de que a produção de alimentos poderia converter-se em um procedimento técnico aos moldes industriais. Esse mesmo autor define três processos que acredita coexistirem na agricultura atual: a desativação, a industrialização e a recampenização.

As três trajetórias interagem em movimentos e níveis diferentes. A desativação se explica pelas grandes áreas agricultáveis abandonadas, substituídas por áreas de conservação ou por avanços da urbanização. Já a industrialização representa os propósitos da modernidade transformando e uniformizando os modos de produção e a cadeia como um todo. Ao contrário da industrialização, o movimento de recampenização é defendido como uma saída para os conflitos em torno da questão ambiental originada pela modernidade. Caracteriza-se pela afirmação da não extinção da agricultura camponesa, presente em quase todos os lugares. Defende que o camponês possui uma posição de agente e é consciente das suas necessidades e possibilidades (PLOEG, 2008). Neste sentido, o autor desenvolve um conceito que agrega as características constituintes do modo de vida do camponês que define como a "condição camponesa". Esta última está vinculada a diversos fatores, tais como: o enfrentamento de um ambiente hostil, de marginalização, de submissão, de privação e de dependência e, por isso, sempre na luta pela autonomia. A autonomia, nessa condição, marcada pela adversidade, caracteriza-se como

processo contínuo de construção, aperfeiçoamento, ampliação e defesa de uma base de recursos autocontrolada, sendo a terra e a natureza viva (cultivos, animais, luz solar, água) suas partes essenciais (PLOEG, 2008, p. 20).

Outro fator essencial à "condição camponesa" se refere à ideia de coprodução, que se refere à interação e à transformação mútua constante entre Homo sapiens e ambiente biofísico. A transformação do ambiente biofísico pela intervenção do agricultor camponês permite alianças entre agricultor e ambiente, podendo em alguns casos acelerar os processos biofísicos, ao mesmo tempo em que transforma o próprio agricultor e the permite garantir seus meios de vida. A relação de coprodução favorável para ambas as partes beneficia o exercício da autonomia do agricultor, reduzindo sua dependência em relação ao mercado industrial (PLOEG, 2008, p. 40). O mesmo autor compreende que a diversificação 
das atividades no meio rural, a pluriatividade, ${ }^{5}$ se constitui como um fator intrínseco à condição camponesa. Além disso, destacam-se as relações de cooperação presentes entre as famílias dos camponeses, com vistas a se tornarem menos vulneráveis às variações do mercado industrial ou às intempéries climáticas.

Trata-se de uma realidade em constante movimento, pois se os camponeses coexistem e resistem ao modo "imperial" de se fazer agricultura, há fortes processos sociais no campo que permitem essa coexistência. Essa autonomia do agricultor, ou a luta por ela, também pode ser percebida pelos engajamentos em movimentos de resistência e de defesa dos próprios interesses (BRANDENBURG, 2008).

A ideia de autonomia, elemento fundamental à compreensão dos contornos do sujeito e à condição camponesa, também se refere à construção de si próprio a partir de seus sentidos para a ação. Porém, defender seus próprios sentidos não significa ignorar os sentidos do outro, compreendendo o outro enquanto um sujeito em potencial. A autonomia em relação aos projetos de vida dos agricultores se relaciona à possibilidade de autogestão de suas vidas, decidindo sobre suas condições materiais e imateriais de sobrevivência, o que, para o caso dos agricultores, se refere também à gestão de sua base de recursos tangíveis e intangíveis (insumos, sementes, conhecimentos, organizações sociais, valores, etc.) e dos meios de comercialização, especialmente os que privilegiem o contato com o consumidor (PLOEG, 2008, 2010).

Outras formas de garantir a autonomia na produção agrícola seriam a diversidade de cultivos e a busca de crédito informal (acordos entre grupos de agricultores, associações, etc.) (PLOEG, 2010). A diversidade na organização da propriedade é defendida também por Assis (2006), pois se alia à condição de diversificação dos agroecossistemas, um dos princípios da produção agroecológica.

É importante ressaltar que as concepções de resistência e autonomia, aqui apresentadas, desenvolvem-se em ambiente hostil, pois a tendência imperial, representada por uma agricultura sempre dependente de insumos externos, longe de estar restrita à agricultura, é, antes, a expressão nesse nicho de um processo paradigmático engendrado pela sociedade englobante. Tal paradigma se manifesta na tecnificação e na exclusão de outras formas de saber que não o científico

\footnotetext{
${ }^{5}$ A pluriatividade é aqui entendida como o desenvolvimento de diversas atividades no contexto da propriedade rural, por exemplo, as atividades de turismo rural, a vinculação a programas de prestação de serviços ambientais, o beneficiamento de produtos, entre outros (PLOEG, 2010).

Cad. de Pesq. Interdisc. em Ci-s. Hum-s., Florianópolis, v.14, n.104, p.25-46, jan/jun 2013
} 
moderno. No olhar atento e crítico de Heidegger (1994, s/p),

o mundo aparece agora como um objeto sobre o qual o pensar que calcula dirige seus ataques, e a estes nada mais deve resistir. A natureza torna-se um único reservatório gigante, uma fonte de energia para a técnica e a indústria modernas.

O trecho torna visível a insatisfação de Heidegger face à ideia de (dis)sociação entre um sujeito que se autoafirma, transformando o ambiente em objeto de domínio. Em lugar desse sujeito (dis)sociado de seu ambiente, herdado de Descartes (1999) e Kant (1999), Heidegger sugere um sujeito (re)conciliado com o ambiente. A crítica de Heidegger não está direcionada exclusivamente a Descartes e Kant, mas às ambições colonizadoras de todos os projetos eurocêntricos modernos. Neste sentido, Heidegger (2004), ao fazer alusão à crise habitacional, não se refere a uma simples falta de moradias, mas a um preocupante processo de desenraizamento do Homo sapiens enquanto ser que busca no ato de habitar a dimensão profunda de sua existência. Habitar, na formulação de Heidegger, significa se demorar junto às coisas, resguardá-las e cultivá-las para que sejam o que são. Opõe-se assim à lógica representada por uma agricultura moderna gerida desde fora, em que os produtos e a própria Terra estão convertidos em mercadoria.

É possível pensar a condição camponesa, cujo processo produtivo é parte de um todo social e culturalmente significado, que está prenhe de relações não mercantilizáveis e que tem como meta a satisfação de necessidades endógenas, como possibilidade concreta de (re)significação do sujeito.

Portanto, tomando-se como referência essa concepção de "habitar", herdada de Heidegger, as práticas de subsistência aproximam os estilos de vida camponeses dos ecossistemas, possibilitando relações mais harmônicas com o ambiente, a despeito dessas formas singulares de se relacionar com o ambiente serem sistematicamente descredibilizadas pelos arautos da sociedade englobante. Nesta forma de "habitar", o camponês nunca separa vida de saber, uma vez que mistura ambos no ritmo de seu trabalho, desde a jornada diária até os ciclos sazonais. Utilizando os recursos de que dispõe, seu saber-fazer se entretece ao entorno que, por sua vez, Ihe devolve o sopro da vida. O viver e o sentir do camponês não subjuga o ambiente, em vez disso, estabelece relações de reciprocidade que salvaguardam a vida de ambos os polos da relação.

Em certa medida, o anúncio dessas outras possibilidades para a agricultura Cad. de Pesq. Interdisc. em Ci-s. Hum-s., Florianópolis, v.14, n.104, p.25-46, jan/jun 2013 
podem ser apreendidas como anúncios de um novo sujeito, de um sujeito (re)significado a partir da prática agroflorestal, mas igualmente (re)significante da mesma.

\subsection{Anúncios de um novo sujeito}

Em conformidade com compreensão de Heidegger, o sujeito derivado do cogito de Descartes (1999) é um sujeito que se opõe ao ambiente. Em perspectiva similar, o sujeito derivado do conceito de sujeito cognoscente de Kant (1999) é o sujeito que também se (dis)socia do ambiente sociocultural e biofísico. Como primeira alternativa, o sujeito derivado do dasein de Heidegger (1999) nega qualquer espaço para esse sujeito oposto ao ambiente e propõe um sujeito que só se constitui de forma conjunta ao ambiente. A segunda alternativa encontra inspiração nas formulações de Morin (2005), cujo projeto epistêmico permite associar as concepções de sujeito anteriores (Descartes/Kant e Heidegger), preservando suas singularidades. Nesta perspectiva com pretensões integradoras, os contornos do sujeito, para Morin, constituem-se a partir de três fundamentos:

1. situa-se no centro do seu mundo para computá-lo e computar-se;

2. opera uma disjunção ontológica entre Si e não-Si; e

3. opera a autoafirmação e a autotranscendência de Si (MORIN, 2005, p. $52)$.

Nos dois primeiros fundamentos, Morin está dialogando com o sujeito ensimesmado, o sujeito (dis)sociado do ambiente de Descartes e de Kant. No terceiro fundamento, Morin dialoga, simultaneamente, com Descartes, Kant e Heidegger e, com isto, permite que se possam estabelecer os contornos de um sujeito, fortemente associado à capacidade não apenas de se autoafirmar (DESCARTES, 1999; KANT, 1999), mas, também, de se autotranscender (HEIDEGGER, 1999). Resta verificar nos depoimentos se o sujeito que emerge da prática agroflorestal se aproxima ou se distancia desses contornos inspirados na concepção de Morin. É o que veremos na seção seguinte. 


\section{Contornos da agrofloresta}

O histórico dos agricultores associados à COOPERAFLORESTA, ${ }^{6}$ ainda que nem todos sejam quilombolas, ${ }^{7}$ está ligado ao histórico dos ciclos produtivos que se fizeram enquanto expressão de um modelo colonizador. Calcados na escravidão, na acumulação e escoamento do capital e no favorecimento das lavouras de plantation ${ }^{8}$ (FURTADO, 1969), em detrimento de uma vasta população camponesa, que chegou a ser reputada como inexistente, tais ciclos impuseram situações sociais, culturais e políticas semelhantes, o que fez com que populações heterogêneas tivessem de enfrentar desafios comuns, gerando diferentes formas de "resistir" e "(re)existir" (LEFF, 2006).

Cumpre ressaltar que a região do Vale do Rio Ribeira do Iguape (Figura 1), onde está localizada a COOPERAFLORESTA, foi uma das primeiras regiões onde se encontrou ouro no Brasil, se constituindo enquanto cenário de alguns dos primeiros contatos entre portugueses e indígenas, mas, também, entre esses indígenas e os africanos escravizados. Após a brusca diminuição da extração do ouro, que deu lugar à mineração de chumbo e alguns outros minerais (séc. XVIII), a região também teve um curto, mas importante, ciclo de produção de arroz que, além de abastecer a capital do Império (séc. XIX), então a cidade do Rio de Janeiro, gerava excedentes a serem exportados. A expansão econômica e social engendrada por esses ciclos foi a responsável pelo aporte de escravos na região, ao passo que a retração e o abandono de áreas geravam um contingente de escravos não propriamente alforriados, mas ao se tornarem livres da mão opressora do senhor, transformaram-se em camponeses responsáveis pela formação de várias comunidades quilombolas na região (ANDRADE et al.., 2000; CARENO, 1995; VALENTIN, 2006; DIEGUES, 2007).

\footnotetext{
${ }^{6}$ Associação dos Agricultores Agroflorestais de Barra do Turvo/SP e Adrianópolis/PR. $<$ http://cooperafloresta.org.br/>.

7 Locais isolados e ocupados por negros fugidos.

${ }^{8}$ Sistema agrícola centrado no seguinte tripé: monocultura exportadora, mão-de-obra escrava e latifúndio.
}

Cad. de Pesq. Interdisc. em Ci-s. Hum-s., Florianópolis, v.14, n.104, p.25-46, jan/jun 2013 


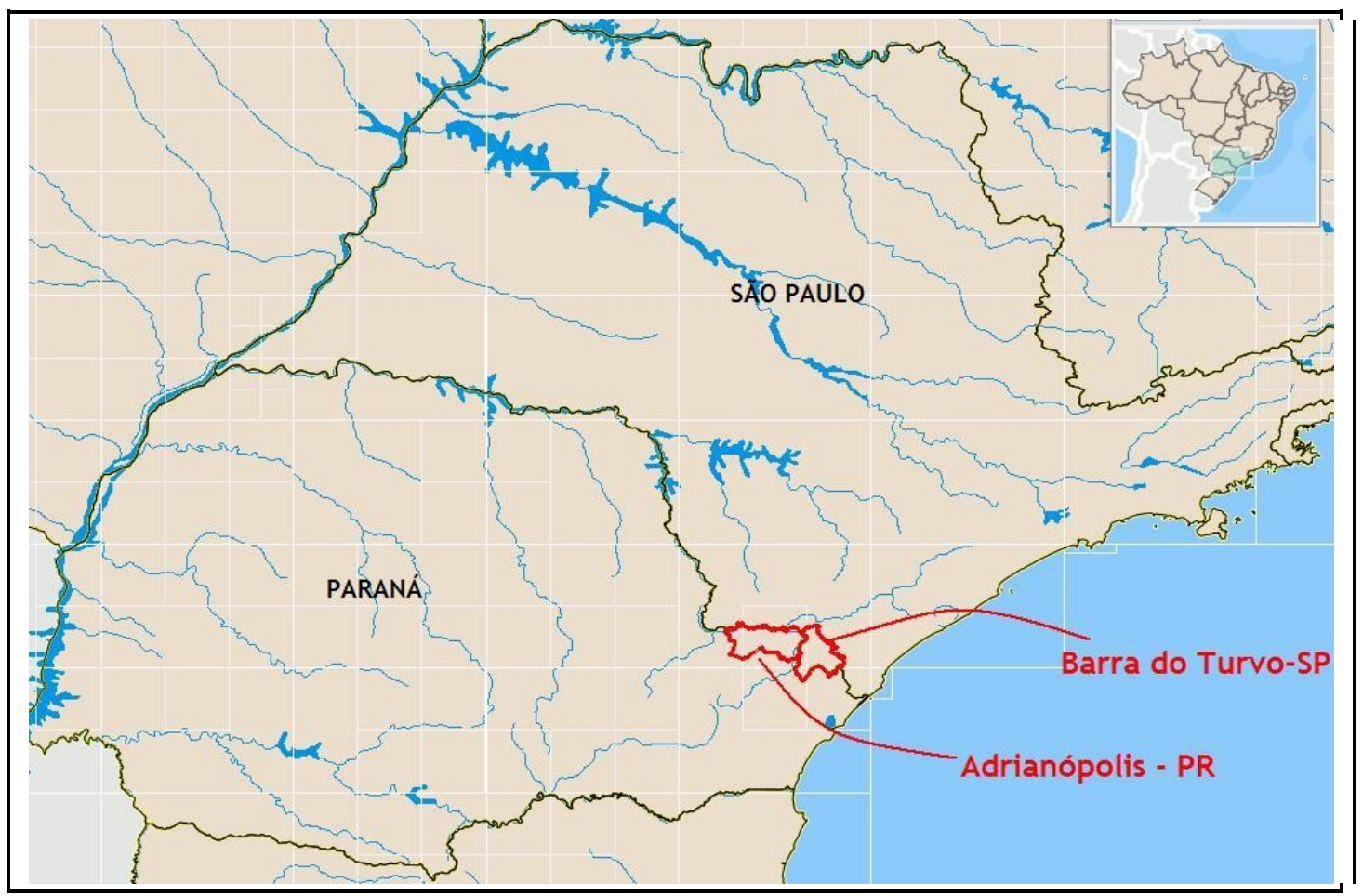

FIGURA 1: Localização da Barra do Turvo e Adrianópolis destaque dos pesquisadores. FONTE: IBGE, 2010.

Os modos de produção das populações tradicionais que habitam o território brasileiro normalmente aparecem como fruto de diferentes níveis de hibridação entre tribos indígenas, africanos e colonos portugueses ou de outras etnias europeias. Quanto mais incipiente o grau da produção voltado para a comercialização de larga escala, tipicamente direcionada para o exterior e promotora de um desenvolvimento deformado, maior a harmonia entre os sistemas naturais e as formações sociais, porque são baseadas num potencial produtivo desses ecossistemas naturais (LEFF, 2009). No caso da região em que foi realizada a pesquisa, foi possível verificar que embora sua condição não fosse a de isolamento, a troca de excedentes se resumia a uma pequena quantidade com vistas à aquisição de víveres como sal, querosene, pólvora e algum tecido (VALENTIN, 2006).

Os agricultores (agrofloresteiros) em questão são vistos assim a partir desse pano de fundo comum. É importante ressaltar que o momento em que começam a implantar o sistema agroflorestal, meados da década de 1990, era um momento crítico, uma vez que o confronto com a sociedade englobante mais uma vez colocava limites claros ao seu modelo tradicional de desenvolvimento. Tal momento se caracterizava, sobretudo, pela crescente onda de concentração fundiária e pela baixa dos preços dos gêneros alimentícios, ambos os fatores geravam uma 
superexploração das parcelas de cultivo, que diminuídas não passavam mais pelos períodos de pousio ${ }^{9}$ e se tornavam constantemente menos férteis.

Nesse movimento de coexistência tensa com a sociedade englobante, os associados da COOPERAFLORESTA começaram a construir espaços de resistência, desenvolveram processos de organização sociocultural que não se submetiam às diretivas impostas por modelos hegemônicos de produção de alimentos. As resistências, conforme observadas em campo, não se configuram como modelos inertes de desobediência civil, mas como engajamento em um movimento coletivo e na construção de modelos alternativos (PLOEG, 2008).

Portanto, é no momento em que a pressão exercida pela sociedade englobante desafia a possibilidade de permanecerem fiéis ao seu projeto de vida que esses camponeses passam, a partir da assimilação de um modelo produtivo alternativo, que já traz em seu bojo o diálogo entre tradição e modernidade, a reconstituir seus "modos de existir". A questão é que isso não se pauta somente numa revalorização da tradição, mas, também, na formação de alianças com saberes que desafiam as linhas abissais traçadas pelo cânone científico moderno (SOUSA SANTOS e MENESES, 2010) e que, portanto, abrem "espaço" para a sua afirmação e valorização perante parcelas sempre maiores da sociedade.

A necessidade de compreender os contornos desses sujeitos emergentes agricultores agroflorestais - nos conduziu à constatação de que eles não se (dis)sociam do seu saber-fazer e viver. A força desse processo de resistência, além de alicerçada na busca pela manutenção e afirmação de uma forma de viver, radica, sobretudo, numa concepção de si plena de sentido que emerge de um processo de auto-socio-eco-educação (MORIN, 2002). Essa concepção de educação está alicerçada na inseparabilidade dessas três instâncias, sem deixar de se referir a cada uma delas em suas especificidades. A educação de si, a partir de uma atitude de busca perante o mundo, reconhecendo-se como responsável por seu próprio processo de educação vivendo formas de comunidade e solidariedade com o outro, o ambiente.

Concomitantemente à emergência desse novo espírito instituído e reforçado pela prática agroflorestal, é oportuno explicitar alguns princípios da agrofloresta que permitem a compreensão dos processos que definem os contornos do sujeito

\footnotetext{
${ }^{9}$ Descanso dado a uma terra cultivada, com vistas a interromper a cultura por um ou mais anos.
}

Cad. de Pesq. Interdisc. em Ci-s. Hum-s., Florianópolis, v.14, n.104, p.25-46, jan/jun 2013 
agroflorestal:

a) engajamento e condução de movimentos coletivos em prol dos direitos humanos e de novas formas de produção;

b) desenvolvimento da agrofloresta como uma proposta de vida;

c) processo de gestão participativa na organização da Associação;

d) organização de trabalho e capacitação por meio de mutirões; e

e) valorização da fé nos projetos de vida.

As ideias de autoafirmação e autotranscendência, responsáveis pela (re)significação do sujeito (MORIN, 2005) face ao ambiente, são o cimento que permite a articulação entre os princípios definidores dos contornos da agrofloresta. Em cada um dos princípios há uma ênfase na dimensão coletiva, sem que isso implique descuido em relação à dimensão individual.

\section{Contornos do sujeito agroflorestal}

Nesta seção, são apresentados os depoimentos colhidos em campo, com vistas a indagar em que medida os contornos deste sujeito agroflorestal aproximamse ou distanciam-se do sujeito abstrato, estabelecido na seção 2 , e dos princípios que definem os contornos da agrofloresta (seção 3).

\footnotetext{
Depoimento 1

E o que eu penso é que o mundo não tá pronto ainda, ele está sendo feito a cada dia e agora a gente tá tendo a nossa oportunidade de também ajudar nessa, como é que eu vou chamar, nessa "fazeção" do mundo. E eu acho que é o fato de muita gente estar doente, depressão, é falta de saber disso! Sabe, você... não tem sentido, não... porquê tem bactérias, tem coisas assim minúsculas que segundo o que dizem alguns, nem cérebro não tem e elas sabem qual que é a função delas e elas executam com perfeição. E agora nós com tudo isso de...e dizer que somos o topo da cadeia alimentar e tudo mais, ficamos loucos, a gente destrói o mundo a nossa volta. Suicídio? Assim consciente, e mas é um suicídio! E esse trabalho (agroflorestas) te dá a possibilidade de você compreender isso e de você fazer parte do todo e penso eu que inclusive, se curar desse vazio que as pessoas têm (Agricultor grupo Córrego do Franco).
}

A expressão espontânea do agricultor - "fazeção do mundo" - é reveladora, pois está associada à confiança dele na ideia de que a agrofloresta é uma possibilidade de compreender de forma holística que todos os seres fazem parte do todo e que por intermédio dela (agrofloresta) também será possível a cura "desse vazio que as pessoas têm". O agricultor constrói um vínculo entre sua capacidade de 
(re)inventar o mundo (a fazeção) e a agrofloresta.

\begin{abstract}
Depoimento 2
A associação dos quilombos já tá com seis anos. Ela veio dos tempos dos meus antepassados. Meus avós vieram lá de Iporanga e Indaiatuba, que fica lá do outro lado do rio. Vieram pra fazer roça, aqui era mata virgem. Eles eram descendentes de negros desses tempos de escravos. Eles eram umas pessoas meio corridas né, descendentes de negros. A minha mãe contava que eles eram umas pessoas muito sofridas, a avó dela era pegada a laço era índia misturada daí casou. Daí de lá eles vieram aqui nessa beira de rio aqui (Terra Seca) eles traziam farinha de lá, acampavam na beira do rio e pescavam peixe com ferramenta e armadilha, cascudo pra fazer sopa, daí eles abriram a roça aqui, dessa época em diante foram aumentando, daí foram buscar as mulheres que tinham deixado lá. Vieram dois casais de lá as duas moças eram irmãs. Construíram as casinhas deles e fizeram as primeiras rocinhas. $\mathrm{E}$ tinha muito bicho aqui, peixe, carne de anta. Daí eles combinaram, uns ficaram aqui (Terra Seca), outros lá no Ribeirão Grande. A minha mãe era a mais nova da família deles. Daí vieram os fazendeiros querendo comprar, aí eles entregaram de mão beijada. Achavam que aquele dinheiro valia. Aí perdiam a terra e o dinheiro, porque dinheiro evapora. Minha mãe é falecida, ela teria uns 79 anos. Daí agora naquelas igrejas católicas, eles que puxaram esse movimento pelos direitos, eles criaram esse negócio de quilombo ai dizendo que eles eram muito discriminados. Daí criaram a associação e hoje está aí (Agricultora do Bairro Terra Seca, Associada à COOPERAFLORESTA e à Associação dos Quilombolas).
\end{abstract}

Neste depoimento, a relação entre agrofloresta e sujeito parece estar no início, vez que se trata de um depoimento que relata um pouco da história, do encontro entre quilombolas e agrofloresta. A brecha para pensar os contornos do sujeito se abre à medida que o agricultor faz referências ao início da luta pelos direitos humanos, liderada por religiosos ligados ao cristianismo católico.

\begin{abstract}
Depoimento 3
A agrofloresta é uma área da propriedade que é produtiva o ano todo e com isso ai a gente se torna mais feliz. Que é uma poupança que estamos fazendo na própria terra, né! Nem que não tenha dinheiro na conta, lá bastante... Mas temos as planta produzindo aí. Vendo a natureza falando com a gente né! Através dos passarinhos e tudo! Porque a natureza ela conversa, e a gente precisa saber conversar com ela também, né! Então, vamos aprender a viver com a natureza (Agricultor do Grupo Ribeirão Grande).
\end{abstract}

Existe uma profunda capacidade de levar em conta a racionalidade não produtivista, mas produtiva do ambiente biofísico. Ao identificar a agrofloresta como uma poupança (e não como um depósito de rejeitos ou como fonte inesgotável de recursos que geram lucro - representação dominante na economia política), o Homo economicus parece ceder um pouco de espaço ao Homo ecologicus. Este último parece ter desenvolvido ou reavivado a capacidade de se (re)conciliar com o 
ambiente biofísico, bem ao contrário do Homo economicus, perito na capacidade de se (dis)sociar do ambiente biofísico. Neste sentido, os contornos do sujeito que irrompe do Homo ecologicus estão diretamente associados à agrofloresta. Falar com a natureza é a forma metafórica desse novo sujeito declarar seu vínculo de (inter)dependência em relação ao ambiente biofísico.

\begin{abstract}
Depoimento 4
É muito mais do que a relação com as plantas, é aquela pergunta assim: será que eu interferindo aqui, o resultado da minha interferência vai gerar saldo ou vai virar dívida? Entende? Essa consciência de questionar porque que eu vou fazer alguma coisa será que isso vai valer a pena, o mundo vai ficar melhor depois que eu fizer isso? Para mim este é um pensamento agroflorestal, não precisa ser na roça, em qualquer outra coisa (Agricultor do grupo Córrego do Franco).
\end{abstract}

O sujeito que irrompe do trecho é o sujeito contido, cuidadoso em relação às suas próprias intervenções no emaranhado da vida. De forma absolutamente contrária ao que é predominante no mundo das coisas e da racionalidade instrumental, o cálculo fecundado pela agrofloresta é posto em dúvida, é submetido ao crivo da prudência e da precaução. O cálculo continua presente e fundamental, mas a diferença é que não é mais soberano. O ethos agroflorestal aparece como um obstáculo ao cálculo que costuma ser apreendido como um fim em si mesmo. A metamorfose do cálculo, de fim em meio, parece ser um indicador dos contornos de um ethos que possibilita um sujeito agroflorestal.

\footnotetext{
Depoimento 5

Para mim, eu acho que até este goiabal misturado com o pasto é um sistema agroflorestal. Eu acho que a atitude da pessoa ela é uma agrofloresta, não é só a área de roça, é um jeito de ver o mundo diferente que... é um outro paradigma, para mim isto é uma agrofloresta, porque eu acho que você pode fazer agrofloresta em todas as suas atitudes não precisa ser só plantando. Vai desde o jeito que a gente trata um cachorro, ou que a gente trata uma criança, que a gente trata um bicho, que a gente trata uma planta....é eu acho que isso tudo é uma atitude agroflorestal. $\mathrm{O}$ que você me diz disso, é só fazer uma agrofloresta, e plantar árvores e não se relacionar com as pessoas, ou com os bichos, não é agrofloresta! Eu acho (Agricultor grupo Córrego do Franco).
}

O trecho permite identificar os contornos do Homo holisticus, capaz de ver a agrofloresta como um intercessor (DELEUZE, 1992), como uma fonte de inspiração que o transforma de forma profunda, que lhe permite fecundar não apenas sua relação com a floresta em si, mas com todos os seres humanos e não humanos. $O$ sujeito que emerge deste Homo holisticus (Di BIASE, 1995) aprende a orientar sua 
existência a partir de outra episteme, fundada não apenas na (dis)sociação, mas igualmente na (re)conciliação entre sujeito e ambientes biofísico e socioculturais. Nesta perspectiva, a agrofloresta além de produzir a vida material do novo sujeito, fornece elementos para que este se realize igualmente nos domínios que transcendem o mundo da matéria.

\begin{abstract}
Depoimento 6
Eu vejo a Cooperafloresta que nem um ônibus, cheio de gente, só que não tem motor ... são pessoas que empurram esse ônibus. Então cada vez que um ta lá dentro, acorda e ajuda a empurrar ele vai ficando mais leve, mais rápido..é assim que funciona. Tem gente que só fica lá dentro reclamando, mas uma hora ele começa a despertar e aí ajuda a empurrar... e é gozado que aí cessa a reclamação porque percebe a qualidade e a natureza das coisas (Presidente da Associação).
\end{abstract}

No trecho, o que permite a passagem de posições de apatia crítica (reclamação em si mesma) à prática crítica (ato de empurrar) é a agrofloresta. Os contornos do sujeito nunca estão dados a priori, mas emergem a partir da combinação de um emaranhado de fatores que permite lançar o primeiro lampejo. São contornos que se compõem e (re)compõem junto ao coletivo, nunca contra ele.

\begin{abstract}
Depoimento 7
Daí nessa época a minha vida foi só mudando né. Mas eu esperava o marido pra resolver as coisas, ele saiu pra trabalhar fora. Eu construí essa casa. Ai fui me esforçando assim, mais que eu era uma pessoa livre para mim cuidar dos meus filhos, eu que não tinha uma pessoa comigo né. Daí pra frente eu me soltei. A COOPERA me ajudou muito e também eu tive necessidade de me virar né, eu tinha que dar roupa, dar calçado e escola. Eu tinha mais saúde, mais força. Enfrentei e hoje eu só tenho que agradecer a Deus né, porque enquanto minhas plantas tá no mato, eu to não to dando conta de limpar, Deus tá tomando conta a natureza tá tomando conta (Agricultora do grupo Terra Seca).
\end{abstract}

É evidente que a entrevistada não faz qualquer menção à sua conquista à condição de sujeita, mas o fato é que ela atribui sua emancipação ("necessidade de me virar") ao coletivo, expressado como "COOPERA" e ao plano espiritual (Deus). É notável que se trata de uma condição de sujeito centrada na ideia de limite, na ideia de que o "outro" (o coletivo da coopera e Deus) emerge como condição sine qua non à busca da emancipação. Não há nenhum culto à ideia do "bastar-se a si mesmo", mas por ser esta uma ideia equivalente à "autoafirmação", não é desprezada.

Depoimento 8

[...] Por que quando a gente não tem esta consciência [possibilitada pela agrofloresta], eu acho que é certo de pensar que tudo aquilo que a gente

Cad. de Pesq. Interdisc. em Ci-s. Hum-s., Florianópolis, v.14, n.104, p.25-46, jan/jun 2013 
põe a mão a gente destrói, mas depois desta consciência, não é assim mais. Eu não tenho medo algum de destruir coisa alguma, porque eu sei que não destruo. Embora para alguns, os tais dos "ecochatos", né? Não se derruba uma árvore nunca. O crime mesmo é não deixar elas crescerem, não deixar que elas existam [...] (Agricultor grupo Córrego do Franco).

Por intermédio da agrofloresta, o trecho revela a emergência de um sujeito sintonizado com princípios conservacionistas, pois nele estão contidas ideias profundas de que é possível a coexistência entre estilos de vida que sabem manejar o ambiente biofísico, com vistas a garantir condições objetivas de reprodução material e espiritual tanto dos humanos quanto dos não humanos. Trata-se de um sujeito que (re)conhece de forma empírica a noção de coevolução (NORGAARD, 1994) dos ambientes biofísicos e socioculturais.

\footnotetext{
Depoimento 9

A: O que é o mundo pra você?

B: Ora, essa pergunta é difícil, não sei o que dizer assim de pronto.

A: Por que pra mim existe assim esse mundo dos homens, que tanto falam, que querem dizer que é isso ou aquilo. Mas se você olhar bem vai ver que existe um mundo da natureza, que não para, ele tá sempre ali, os insetos e as plantas trabalhando, e nós também fazemos parte desse mundo

B: Pensando nisso o que mais me impressiona na Natureza é que não importa o jeito que você trate ela, ela sempre faz a vida crescer, ela sempre quer arrumar tudo de novo!

A: Não é isso que chamam de amor incondicional?!
}

Neste trecho, não há qualquer vínculo explícito entre agrofloresta e sujeito. Contudo, o trecho permite tornar visível um sujeito radicalmente influenciado por uma ética do cuidado, capaz de atribuir ao ambiente biofísico uma racionalidade centrada no amor incondicional. Numa concepção dessas, parece haver pouco ou nenhum espaço para relações abusivas entre este tipo de sujeito e o ambiente biofísico.

\footnotetext{
Depoimento 10

Cada pessoa vai ter uma forma de fazer e ainda que seja numa mesma direção ninguém vai fazer igual. A agrofloresta de cada um vai ser uma marca pessoal. Nem a gente faz uma agrofloresta igual a outra. Eu acho que o estado de espírito das pessoas também interfere. Talvez a própria fé que a gente tem na vida (Agricultor grupo Córrego do Franco).
}

Neste trecho, há um acento maior num sujeito ensimesmado, contudo, é possível destacar que a menção à agrofloresta tende a caracterizá-la como um intercessor (DELEUZE, 1992), como uma possibilidade de emancipação. 


\title{
Depoimento 11
}

Eu acredito que se você cumpriu bem a sua função, o mundo e todas as energias que nele existem vão suprir as suas necessidades... para mim é isso o básico de tudo ... Então é isso, eu acho que, tipo assim, eu não sei se a gente é agricultor, se a gente é jardineiro ou a gente é só ser humano. Não dá para rotular! E pense assim, se você fosse Deus e tivesse um jardineiro, você ia querer ver o seu jardineiro na miséria? Pois é, é nisso que eu acredito, que quando a gente trabalha neste jardim a abundância vem naturalmente não é um lugar para ter miséria (Agricultor, grupo Córrego do Franco).

O trecho não traz de forma explícita qualquer evidência de vínculo causal e causante entre agrofloresta e sujeito emergente. Contudo, traz uma concepção de sujeito distante da imagem do conquistador/predador e mais próxima daquele ser que aprendeu a cuidar, o jardineiro do Planeta.

\begin{abstract}
Depoimento 12
Então por menos que a pessoa esteja consciente ela também ta botando a ficha dela com isso, E talvez a ficha dela seja do tamanho da minha ou maior, porque cada um põe a ficha que tem né?... então se ela tem a consciência que imagina que eu tenho, a minha contribuição deveria de ser infinita eu luto pra entender. O normal é viver o agora e amanhã a Deus pertence né... é só a continuação do hoje... não dá pra esperar que a vida seja ruim se você planta fruta. Como pode ser ruim? Não faz sentido. Você se cultiva a si próprio. Acaba atraindo coisas boas... ah, sei lá... não deveria de ter essa preocupação com o que vai ser, talvez o ideal é que o agora me baste e pronto (Agricultor do Córrego do Franco).
\end{abstract}

Neste trecho, há um acento maior num sujeito ensimesmado, sobretudo quando o entrevistado, além de não fazer qualquer menção à agrofloresta, faz referência à necessidade enfática de valorização do presente e de cultivo de "si próprio". A ênfase do depoimento está direcionada à "autoafirmação" desvinculada da "autotranscendência". Trata-se dos contornos de um sujeito muito próximo do sujeito derivado do cogito cartesiano, o sujeito (dis)sociado do ambiente.

\begin{abstract}
Depoimento 13 (TÉCNICO)
A agrofloresta acaba mexendo na crença da pessoa, mas ela tem que acreditar. Se você acredita em Deus, o quando você está vendo disso, a gente é o que a gente acredita. Agrofloresta é um processo de iniciação espiritual, eu não tenho dúvida disso, é fruto da comunhão, esse sentimento de amor, de Deus está muito presente na COOPERAFLORESTA. E a própria linguagem técnica está cheia destes elementos de ligação com a natureza, e de unidade da vida. $E$ isso é diferente do mercado hegemônico, é antagônico. E tem um componente da fé que já existia aqui. Houve uma mudança do meu discurso em agrofloresta muito grande, eu já era uma pessoa muito religiosa quando eu cheguei aqui. Eu percebia que havia uma relação entre agrofloresta e a espiritualidade. Deus está presente em toda a natureza e de qualquer forma nessa organicidade imensa na natureza, que gosto de chamar da presença de Deus na natureza. Se você não usa essa língua da espiritualidade, que é a língua como os povos das Américas
\end{abstract}

Cad. de Pesq. Interdisc. em Ci-s. Hum-s., Florianópolis, v.14, n.104, p.25-46, jan/jun 2013 
explicavam, quando faziam a agrofloresta. Essa compreensão de que a natureza é viva, de que Deus está ali. Eu acho que um dos elementos do sucesso da COOPERAFLORESTA, não fui eu que trouxe, mas fui encarregado pelas pessoas para esse tipo de fala, a minha forma de explicar tem uma forte contribuição de Ernesto, que também teve uma contribuição dos povos da floresta, aqui isso está tão presente a partir de uma comunhão de saberes de grandes sínteses e de fé que está presente nas falas dos técnicos inclusive (Técnico da Associação).

O trecho é um recorte da fala, não de um agricultor, mas de um técnico que atua entre os agricultores. Talvez o grau de instrução formal do entrevistado explique sua ênfase no vínculo causal e causante entre agrofloresta e emergência de um sujeito (re)conciliado por meio da espiritualidade com os ambientes biofísico e socioculturais.

\section{Depoimento 14 (TÉCNICO)}

Eles tinham tudo pra dizer que a gente era maluco, mas o que ajudou foi que no sistema de derrubada e queimada que eles praticavam, a fertilidade da terra já era recuperada pela floresta, por um período florestal, a porteiras fechadas (Técnico da COOPERAFLORESTA).

O trecho revela um nível de tensão entre duas formas distintas de se relacionar com o ambiente, a dos quilombolas e a da agrofloresta. $O$ técnico parece ter tido habilidade suficiente para implantar a prática agroflorestal, levando em conta a prática tradicional dos agricultores. Parece ser uma estratégia sábia para quem tem pretensões de despertar nos agricultores uma nova sensibilidade, um novo sujeito capaz de se (dis)sociar, mas, também, de se (re)conciliar com o ambiente biofísico e sociocultural.

\section{Diálogo com os achados da pesquisa}

Ao que parece, o sujeito que irrompe dos depoimentos dos agrofloresteiros está distante do sujeito derivado do cogito cartesiano (DESCARTES, 1999), que seria o sujeito ontológico, universal, radicalmente (dis)sociado do mundo das contingências, logo de todos os ambientes biofísicos e socioculturais.

Da mesma forma, esse novo sujeito também parece distante do sujeito cognoscente e autônomo de Kant (1999), vez que este, de forma mais radical do que o sujeito cartesiano, rompe em definitivo com a heteronomia apreendida por Kant como relação de dependência do Homo sapiens em relação ao ambiente biofísico. O sujeito cognoscente de Kant é o sujeito que se (dis)socia em definitivo 
com qualquer dependência do ambiente biofísico. Nas duas perspectivas fundantes de uma episteme reducionista e inspiradora da maioria dos campos disciplinares da modernidade, o sujeito é aquele que se constitui e se (re)constitui como sujeito autônomo à medida que se afasta e se opõe ao ambiente biofísico. Trata-se de um sujeito que se afirma à proporção que transforma tudo que lhe é externo em "coisas", em "objetos" passíveis de serem "controlados". Trata-se igualmente de um sujeito que se afirma negando qualquer identificação com o ambiente biofísico.

Diferente desse sujeito ensimesmado foi possível localizar, nos depoimentos, expressões que remetem a outro sujeito. $O$ traço comum desse sujeito (re)significado é que ele, ao contrário do sujeito de Descartes e Kant, reconstitui-se na convergência entre os contornos de um sujeito abstrato (seção 2) e a materialidade da agrofloresta. Este ponto de convergência é o ponto privilegiado e fecundado por expressões variadas da espiritualidade, da metafísica e das práticas agroflorestais. Este novo sujeito parece estar mais próximo da noção de dasein (daquele ser que só pode/deve ser compreendido na comunhão com outros, nunca isolado), de Heidegger (1999). Contudo, há limites para isso, pois a abordagem de Heidegger parece insuficiente, na medida em que ao negar a (dis)sociação entre sujeito e ambiente, nega qualquer possibilidade de existência e de autonomia do sujeito. Não há lugar para a subjetivação, no conceito de dasein de Heidegger.

Diante dessa dificuldade, parece que Morin (2005) oferece uma explicação mais emaranhada para este sujeito emergente, pois o pensador francês consegue (re)conciliar o sujeito ensimesmado de Descartes e Kant com o sujeito diluído no ambiente de Heidegger. Em uma formulação inspirada em Morin, este sujeito emergente - o sujeito agroflorestal - é um sujeito que se (re)concilia com os ambientes socioculturais e biofísicos, pois consegue (re)conciliar as capacidades de se autoafirmar e se autotranscender. Há uma (re)significação do conceito de sujeito, pois o sujeito que irrompe dos depoimentos, ao mesmo tempo que se (dis)socia do ambiente em busca de sua singularidade, (re)concilia-se com o mesmo ambiente ao reconhecer sua dependência em relação a este último.

Esse diálogo sobre o sujeito pode ser inserido no debate mais amplo acerca da constituição do novo campo de conhecimento ambiental, o que abre possibilidades para novas investigações que indaguem até que ponto esta (re)significação do sujeito impacta na (re)significação do campo de conhecimento ambiental emergente.

Cad. de Pesq. Interdisc. em Ci-s. Hum-s., Florianópolis, v.14, n.104, p.25-46, jan/jun 2013 


\section{Considerações: vínculos entre agrofloresta e sujeito}

A ideia desta derradeira seção é tornar visíveis e, de forma sintética, os contornos que permitem identificar os vínculos entre sujeito e agrofloresta. O objetivo do artigo desdobrou-se em dois que foram contemplados e uma nova questão que se abre a novas investigações. Sobre os dois objetivos contemplados, inicialmente a ideia de mergulhar nos depoimentos de agrofloresteiros com vistas a localizar os contornos de um novo sujeito foi bem sucedida, pois foi possível tornar visíveis os vínculos entre as práticas agroflorestais e o novo sujeito. No segundo momento, a ideia de verificar as aproximações entre os contornos desse novo sujeito e concepções consagradas acerca do sujeito, as de saber, Descartes, Kant, Heidegger e Morin foi igualmente exitosa pois, entre os catorze depoimentos, apenas o depoimento número 12 distanciou-se dos outros treze depoimentos. Ao contrário dos outros treze entrevistados, o depoente número 12 não foi enfático em relação ao poder emancipatório da agrofloresta, acentuou a força individual.

Sendo assim, o que é possível concluir é que os contornos do novo sujeito tendem a distanciá-lo das concepções de Descartes e Kant e a aproximá-lo parcialmente de Heidegger, e ainda mais de Morin, na medida em que se trata de um sujeito que, de forma simultânea, (dis)socia-se da "autoafirmação", de Descartes e Kant, e reconcilia-se com, via a "autotranscendência" de Heidegger, com o ambiente biofísico e sociocultural. Neste sentido, é possível identificar no processo ambíguo e recursivo de autoafirmação e autotranscendência, os contornos de um sujeito (re)significado, o sujeito agroflorestal.

No que se refere à questão que emergiu, ela foi percebida ao longo da pesquisa empírico-reflexiva. A partir do diálogo estabelecido entre teoria e empiria, é possível indagar se há possibilidade de aproximar os contornos desse sujeito (re)significado dos contornos do campo de conhecimento emergente, o campo de conhecimento ambiental, vez que se trata de uma questão fecunda para a continuidade da investigação. Essa questão fica indicada para novas investigações. 


\section{REFERÊNCIAS}

ANDRADE, T. et al. (Ed.). Negros no Ribeira. 2.ed. São Paulo: ITESP: Páginas \& Letras- Editora Gráfica, 2000 (Cadernos do ITESP 3).

ASSIS, R. Desenvolvimento Rural Sustentável no Brasil: Perspectivas a partir da integração de ações públicas e privadas com base na agroecologia. In: Economia Aplicada, n.10, v.1. p.75-89, jan./mar. 2006.

BRANDENBURG, A. Colonos: Subserviência e autonomia. In: BRANDENBURG, A. FERREIRA, A. (Orgs). Para pensar outra agricultura. 2. ed. Curitiba: Editora UFPR, 2008 .

CARENO, M. F. Nhunguara: uma comunidade rural do Vale do Ribeira. Rev. hist., São Paulo, n.132, jun. 1995. Disponível em:

$<$ http://www.revistasusp.sibi.usp.br/scielo.php?script=sci arttext\&pid=s0034-

83091995000100006\&lng=pt\&nrm=isso>. Acesso em: 28 set. 2011.

DELEUZE, G. Conversações. São Paulo: Ed. 34, 1992.

DESCARTES, R. Descartes: vida e obra. São Paulo: Nova Cultural, 1999. (Os Pensadores).

DI BIASE, F. O Homem Holístico: a unidade mente-natureza. Petrópolis: Vozes, 1995.

DIEGUES, A. C. O Vale do Ribeira e Litoral de São Paulo: meio-ambiente, história e população. CENPEC, 2007. Disponível em: <http://www.usp.br/nupaub/cenpec.pdf>. Acesso em: 10 mar. 2012.

FONINI, R. Agrofloresta e alimentação: estratégias de adaptação de um grupo quilombola em Barra do Turvo (SP). 197f. Dissertação (Mestrado em Meio Ambiente e Desenvolvimento), Universidade Federal do Paraná, Curitiba, 2012.

FURTADO, C. Formação econômica da América Latina. Rio de Janeiro: LIA, 1969.

GLIESSMAN, S. Agroecología. Procesos ecológicos en Agricultura Sostenible. Turrialba, C. R CATIE, 2002. 
GOOGLE MAPS. Vale do Rio Ribeira do Iguape. Disponível em:

$<$ http://pt.mapatlas.org/Brasil/Corrente de \%C3\%81gua/Rio Ribeira do Iguape/2021

6/3D earth map\#map1>. Acesso em: 13 jan. 2013.

HEIDEGGER, M. Construir, habitar, pensar. Buenos Aires, 2004. Disponível em: http://www.laeditorialvirtual.com.ar/pages/heidegger/heidegger construirhabitarpensar. htm. Acesso em: 10 jan. 2012.

HEIDEGGER, M. Ser e tempo. São Paulo: Nova Cultural, 1999 (Coleção Os Pensadores).

HEIDEGGER, M. Serenidad. Tradução de ZIMMERMANN, Yves. Barcelona: Ediciones del Serbal, 1994. Disponível em: <https://docs.google.com/file/d/0B2n62xD3SgHWNTI5MWMxYmYtOGQxMy00NWlyL WJhZWUtM2ExYjAxYWVhNDg5/edit?pli=1>. Acesso em: 15 jun. 2012.

ICHIKAWA, E. Y.; SANTOS, L. W. Contribuições da história oral à pesquisa organizacional. In: SILVA, A. B.; GODOI, C. K.; BANDEIRA-DE-MELLO, R. (Org.). Pesquisa qualitativa em estudos organizacionais:paradigmas, estratégias e métodos. São Paulo: Saraiva, 2006. p.181-206.

KANT, I. Crítica da razão pura. São Paulo: Nova Cultural, 1999 (Coleção Os Pensadores).

LEFF, E. Racionalidade Ambiental: a reapropriação social da Natureza. Rio de Janeiro: Civilização Brasileira, 2006.

LEFF, E. Ecologia, Capital e Cultura: A territorialização da racionalidade ambiental. Rio de Janeiro: Vozes, 2009.

MARTÍNEZ-ALIER, J. O ecologismo dos pobres. São Paulo: Contexto, 2011.

MARTINS, J. S. Não há terra para plantar neste verão: o cerco das terras indígenas e das terras de trabalho no renascimento político do campo. Rio de Janeiro: Vozes, 1986.

MORIN, E. O método 3: o conhecimento do conhecimento. 3. ed. Porto Alegre: Sulina, 2005. 
MORIN, E. Educação e complexidade: os sete saberes e outros ensaios. São Paulo: Cortez, 2002.

NORGAARD, R. B. Development betrayed: the end of progress and a coevolutionary revisioning of the future. London e Nova lorque: Routledge, 1994.

PLOEG, V. D. Camponeses e Impérios Alimentares: lutas por autonomia e sustentabilidade na era da globalização. Porto Alegre: Editora da UFRGS, 2008.

PLOEG, V. D. Entre a dependência e a autonomia: o papel do financiamento para a agricultura familiar. In: Agriculturas. v. 7, n.2, jul. 2010.

SOUSA SANTOS, B.; MENESES, M. P. (Orgs). Epistemologias do Sul. São Paulo: Cortez, 2010.

VALENTIN, A. Entre o Chuço e o Remo: agricultores e caiçaras no Vale do Ribeira (1800-1880). Anais do XV Encontro Nacional de Estudos Populacionais, Caxambu -MG, 2006.Disponível em:

<http://www.abep.nepo.unicamp.br/encontro2006/docspdf/ABEP2006 494.pdf>. Acesso em: 18 set. 2011.

WANDERLEY, M. N. B. A emergência de uma nova ruralidade nas sociedades modernas avançadas - o "rural" como espaço singular e ator coletivo. Estudos Sociedade e Agricultura, n. 15, p. 87-145. 2000.

WANDERLEY, M. N. B. Agricultura familiar e campesinato: rupturas e continuidade. Estudos Sociedade e Agricultura, Rio de Janeiro, n. 21, p. 42-61. 2003.

YIN, R. K. Estudo de caso: planejamento e método. 3. ed. Porto Alegre: Bookman, 2005.

Artigo:

Recebido em: 13/01/2013

Aceito em: 23/07/2013 